\title{
Hierarchical Relationships in Dependency Grids: Explorations in Survivors of Childhood Sexual Abuse
}

\author{
Richard C Bell \\ University of Melbourne, Australia \\ David Winter \\ University of Hertfordshire and Barnet, Enfield and Haringey Mental Health \\ NHS Trust, U.K. \\ Suchitra Bhandari \\ Barnet, Enfield and Haringey Mental Health NHS Trust, U.K.
}

December, 2009

Address for Correspondence:

Richard C. Bell

Psychological Sciences

University of Melbourne

Victoria 3010 Australia

Ph: +61383446364

Fax: +61393476618

Email: rcb@unimelb.edu.au 


\section{Abstract}

A methodology for representing the patterns of dependency in a dependency grid using partial order scalogram analysis by coordinates (POSAC) is presented. The technique, devised by Shye (1985), shows these patterns as hierarchical relationships which indicate superordinate and subordinate resources. An index of depth of resource support is calculated in addition to an index of breadth of resource (which is shown to correspond to an index of dispersion of dependency. The procedure was applied to data from 54 survivors of child sexual abuse and a similar number of control subjects who all completed both an adult and child dependency grid. There was significantly less breadth of resource in the abuse group, more so for the child version than the adult, but there was significantly more depth of resource in the dependency grids from the child sexual abuse survivors. 
Extracting information from a repertory grid has a long history and encompasses a wide range of methods and summary indices (Fransella, Bell, and Bannister, 2004). However, in stark contrast to this stands the dependency grid, devised by Kelly (1955) and originally known as the situational resources grid, in which the individual indicates to which of a set of resources (usually people) s/he would turn if faced by each of a series of problem situations. The principal summary measure yet derived from such a grid is an index of the dispersion of dependency (Walker, Ramsay \& Bell, 1988), which is relevant to Kelly's (1955) view that dispersion of dependencies across resources, in contrast to 'undispersed dependency', is conducive to psychological wellbeing. This dearth of summary measures limits the usefulness of the methodology in clinical settings as the calculation of a single score rarely justifies the effort required to collect the grid data. It may also limit its use as a research methodology, as there may well be other information in the dependency grid that is not captured by the dispersion of dependency measure. Bell (2001) showed an example of this situation, where seriation of the grid revealed a patterning of dependency not apparent either in the index or in the raw dependency grid itself.

In this study we propose a method of examining hierarchical structures in dependency grid data. Hierarchical structures have received attention in other aspects of personal construct psychology, principally through Hinkle's (1965) laddering innovation, but also within the context of the repertory grid. Hierarchical structure is implicit in the Organization Corollary of Kelly's (1955) theory of personal constructs: 'Each person characteristically evolves, for his convenience in anticipating events, a construction system embracing ordinal 
relationships between constructs' (p. 56). The critical term here is the 'ordinal relationship', which Kelly defined as occurring when 'One construct may subsume another as one of its elements.' (p.57). Bell (2004) reviews some of the confusion that has surrounded this issue over the years, and while approaches have been proposed for identifying such structures in grids (eg Bell, 2004; Gaines \& Shaw, 1981) they have not proven particularly useful. In a sense such structures seem to be imposed on repertory grid data rather than naturally emerging from it. However, perhaps surprisingly, such ordinal relationships are readily seen in the data of a dependency grid.

Suppose a person relies on their mother for some problems with: relationships, money, loneliness, and health, but not anger or sexual problems. The person also relies on their best friend for: relationships, loneliness, and health, but not money, anger, or sexual problems. The best friend therefore helps in a subset of the problems the mother helps with. The best friend is therefore subordinate to the mother as a resource. If we set $1=$ resource, and $0=$ not a resource, we can represent the situation diagrammatically as in Figure 1.

\section{Insert Figure 1 about here}

We can then see how a hierarchical network of such relationships can be represented in the hypothetical dependency grid data shown in Figure 2.

Insert Figure 2 about here

Some years ago in a theoretical paper, Chiari, Mancini, Nicolo, \& Nuzzo (1990) formally (in a mathematical sense) showed that if a construct is subordinate to another, then elements in both poles of the subordinate construct will be subsumed under one and the same pole of the superordinate 
construct. This was, and probably still is, a difficult concept to assimilate within the repertory grid context. However it can be readily seen to hold in the hypothetical dependency grid shown in Figure 2.

However, it is not clear how such hierarchical structures can be detected in real dependency grid data, such as is shown Figure 3 . This grid is from a study of dependency in victims of childhood sexual abuse, for which more details will be given later in this paper.

\section{Insert Figure 3 about here}

A solution is available however. Shye (1985) presented a model (and the Fortran listing of a program) for partial order Scalogram by analysis of base coordinates called POSAC, which orders profiles (in the present case the situation profile for a given resource) to reflect hierarchical relationships among resources as shown in Figure 2. POSAC has been applied in a variety of settings modelling between individual differences (e.g. Porter and Alison (2005) who used it model the behaviour of leaders of sexually violent groups). However, to our knowledge it has not been applied to within person differences such as are found in grid data.

More technically, given profiles for two resources showing availability across a common set of situations, one resource profile is said to be greater than the other only if it is available for at least one situation that the other resource is not available for. Otherwise the two resource profiles are not comparable. POSAC addresses the following question: given a set of observed resource profiles with $n$ situations, can we assign two scores (that is, a twodimensional representation to each resource profile) such that for any two observed resource profiles, their observed relation 'greater than' and 
'incomparable to' would be represented by their corresponding two horizontal (incomparability) and vertical (superordinate) coordinates. POSAC has the advantage of working directly from the data, considering all situations simultaneously (and equally).

POSAC uses an iterative algorithm to find a best fitting configuration of resource-situation profiles that has these features. Figure 4 shows the POSAC representation for the dependency grid shown in Figure 3.

\section{Insert Figure 4 about here}

The POSAC algorithm adds a perfect resource to the dependency grid to enable examination of the links among incompatible profiles. Thus, in Figure 4, 'friend of same sex', 'significant other 2', 'partner', and 'self' have non-overlapping profiles of situations for which they are available. The vertical dimension reflects the number of situations a given resource is available for. Thus, 'sister', who covers some of the situations that 'friend of same sex' does (but not all), is available for more situations than 'partner' and self'. At the bottom of the hierarchy, indicating unavailability for all situations, are the figures of father and the perpetrator, and the figure of 'doctor' is the least available of the other figures. We can see two general hierarchies. One hierarchy, a largely female one, goes through 'friend of same sex' (the client was female), 'sister', then either 'mother' or 'significant other 1 ' to 'brother'. The other strand, a male one, goes through either 'significant other 2 ' or 'partner', to 'friend of the opposite sex' to 'brother' or 'grandpa/grandma'. 'Self', although reasonably substantially available, is an isolated resource.

We can see some of the usefulness of this approach by considering a second grid from the same study, shown in Figure 5. 


\section{Insert Figure 5 about here}

While this dependency grid looks different to the previous one, the dispersion of dependency was fairly similar. The Walker et al (1988) index values (based on a 'sample' of 7, although results were similar for sample sizes of 3 and 10) were 5.27 for the Figure 3 grid and 5.30 for the Figure 5 grid, while the corresponding values of the Bell (2000) index were 0.88 and 0.85 respectively. Figure 6 shows the POSAC representation of this grid.

Insert Figure 6 about here This dependency grid shows a very different pattern of largely independent resource figures. There are few hierarchical chains and a relatively large number of resources that are only nested under the maximal ideal profile. Thus, this person sees different people as resources for different situations, but, unlike the preceding grid, there is little backup for these resource persons and no persons to turn to for a range of situations. Information such as this may well be useful in the therapy process.

From a research perspective simple visual representations are not readily combined in ways that can be aggregated and tested. One way in which we might characterize such diagrams is by the depth of the configuration (excluding the extreme profiles), which gives an indication of the variation in resource availability. Those nearer the top can be depended on in a larger range of situations, those nearer the bottom are more specialized, and thus this represents the variation in coverage. The second characterization is the maximum breadth of the configuration, which is an indication of the degree of non-overlap or differentiation of sets of situations covered by the resources. Indices can be calculated to represent these qualities. The Euclidean distance 
between the extreme points, either vertically (excluding the two extremes) or horizontally, normed by the range gives a value between zero and one. Table 1 shows these indices for the configurations shown in Figures 4 and 6.

Insert Table 1 about here

We can see how these indices might behave by considering the dependency grids used in a study of long-term effects of childhood sexual abuse (Bhandari, 1998; Bhandari, Winter, Messer, \& Metcalfe, 2009).

\section{Method}

\section{The Sample}

The participants were drawn from two populations: students attending university health centres and clients on the waiting list for psychological therapy in a National Health Service Clinical Psychology Department. In each setting, participants were asked to complete a screening questionnaire. On the basis of this, 22 participants in the university sample who reported that they had been sexually abused as children were matched on demographic variables with 22 who had not been abused; and, similarly, in the psychological therapy sample there were 32 abused and 32 matched non-abused participants. In the university sample, 17 of each subgroup of participants were female and 5 male, while the corresponding numbers for the psychological therapy sample were 25 and 7. Mean ages for the university sample were 22.82 years (s.d. 3.33) abused and 22.59 years (s.d. 3.96) non-abused; and for the psychological therapies sample 36.03 years (10.07) abused and 36.94 years (9.47) non-abused.

\section{The Dependency Grids}


The participants each completed two dependency grids in addition to numerous other measures, the results of which will not be reported here. In one, the 'childhood dependency grid', the following list of situations was presented (from Walker et al., 1988):

1. The time when you were most perplexed about planning for your career.

2. The time when you had the greatest difficulty understanding how to get along with the opposite sex.

3. The time when you needed money.

4. The time when you were in poorest health or had a long period of illness.

5. The time when you made a serious mistake.

6. The time when you failed to accomplish something you tried very hard to do.

7. The time when you were lonely.

8. The time when you felt discouraged about the future.

9. The time when you got very angry.

10.The time when you felt ashamed.

11.The time when you felt frightened.

12. The time when you felt most mixed up or confused about things in general.

13. The time when you had serious trouble with your parents, or came nearest to having trouble with them.

14. The time when you had trouble with your sister, brother or close relative or the time when you came nearest to having trouble with one of them. 
15. The time when you had trouble with your girl/boyfriend, or the time when you came nearest to having trouble with him/her.

For each situation, participants were asked to think of a time in their life before the age of 16 years when they were most troubled by it. They were then asked to whom, of the following list of 'resources', they would have gone for help at that time:
A. Father
B. Mother
C. Sister or close female relative
D. Brother or close male relative
E. Partner
F. Friend of the same sex
G. Friend of the opposite sex
H. Doctor

I. Grandmother

J. Grandfather

K. Perpetrator (for abused participants) or significant person (for nonabused participants)

L. Self

M. Significant person

N. Significant person.

Participants also completed an 'adult dependency grid' which was identical to the child grid except that it contained an additional problem situation, concerning trouble with their children, and two additional resources, 
'son' and 'daughter'. They were asked to complete this grid with reference to their life after the age of 18 years.

Grids were analysed by the algorithm of Shye (198?) as incorporated in Gridstat5.

\section{Results}

Correlations among the usual dispersion of dependency measure, the breadth, and the depth of the POSAC hierarchy are shown in Table 2, with correlations for the child grid above the diagonal as italics, and the adult grid below. Correlations between child and adult measures are shown in the diagonal as bold.

Insert Table 2 about here

As might be expected, breadth and depth are negatively correlated, and breadth but not depth correlates substantially with the traditional dispersion of dependency measure.

Repeated measures analysis of variance was used to examine differences between the child and adult dependency grid measures with abuse and control groups and source of subject (clinic vs. university) acting as between subjects factors. Since the source of subjects was not of primary concern, and since this factor, though significant as a main effect (as shown in Table 3) had no significant interactions it was considered first. On both dispersion and breadth measures university subjects scored significant higher than clinic subjects. There were no significant differences for the depth of hierarchy measure.

Insert Table 3 about here

For the factor of interest, abused vs control, we report results separately by measure. 


\section{Traditional Dispersion of Dependency}

Mean scores are shown in Table 4. Higher scores indicate greater dispersion of dependency.

Insert Table 4 about here

For the traditional dispersion of dependency index there were significant differences between the two groups $(F=5.02, d f=1,105 ; p=.027)$, with the abused group having less dispersion of dependency. There were also significant differences between the measures for the child grid and the adult grid $(F=19.98, d f=1,105 ; p<.001)$, with more dispersion of dependency in the adult grid in both groups. There was no significant interaction between the group factor and the repeated measures child-adult grid factor. Breadth of POSAC hierarchy

Mean scores are shown in Table 5. Higher scores indicate greater breadth in the POSAC hierarchy.

\section{Insert Table 5 about here}

For the new measure of breadth of resources as shown in the POSAC diagram, there were significant differences between the two groups ( $F=5.86$, $d f=1,105 ; p=.017$, with the abused group having a smaller breadth of resources. There were also significant differences between the measures for the child grid and the adult grid $(F=30.65, d f=1,105 ; p<.001)$, with greater breadth of resources in the adult grid in both groups. There was a just significant interaction between the group factor and the repeated measures child-adult grid factor $(F=4.01, d f=1,105 ; p=.048)$, with a the difference between groups being greater for the child dependency grid. Depth of POSAC hierarchy 
Mean scores are shown in Table 6. Higher scores indicate greater depth in the POSAC hierarchy.

\section{Insert Table 6 about here}

For the new measure of depth of resources as shown in the POSAC diagram, there were significant differences between the two groups ( $F=5.39$, $\mathrm{df}=1,105 ; \mathrm{p}=.022$ ), with the abused group having a larger depth of resources. There were no significant differences between the measures for the child grid and the adult grid $(F=0.017, d f=1,105 ; p=.898)$, and no significant interaction.

\section{Discussion}

In reviewing research with the dependency grid, Walker (1997), notes 'the potential for exploring more facets of depending using such a methodology than is evidenced by dispersion of dependency' (p. 91). The use of the POSAC algorithm provides one avenue for such exploration by disentangling dispersion of dependencies, much as in the repertory grid literature refinement of measures of the structure of construing (e.g. Landfield, 1983) has allowed a more fine-grained analysis than that provided by global indices. In our study, we have found that dispersion of dependency only relates to the breadth of dependencies, the extent to which situations are differentiated in terms of resources used. It does not relate to the depth of dependencies, the variation in the situations for which resources are used, which may therefore be a useful additional measure of the hierarchical structure of dependencies. The independence of these measures is also indicated by the fact that, although there was greater dispersion and breadth of dependencies in 'adult' than 'child' grids, as might be expected from Kelly's (1955) association of maturity with 
greater dispersion of dependencies, this was not the case with the measure of depth of dependencies.

Our finding of lower dispersion of dependency in survivors of childhood sexual abuse than in individuals who have not been abused is not unexpected. As Erbes and Harter (2002, p. 40) indicate, 'Survivors develop constructions of self and others through participation in family systems that are frequently hostile, closed, or invalidating'. The abuse survivor is likely to have had relationships with caregivers which may be characterised by dependency paths 'initiated by guilt and threat' (Chiari et al., 1994), both of which are likely to be associated with low dispersion of dependencies. Such a pattern might also be expected on the basis of reported tendencies for social isolation (Alexander \& Follette, 1987), and tight external boundaries (Minuchin, 1974), in incestuous families.

Interestingly, however, although the difference between abused and non-abused groups in dispersion of dependency was mirrored in that in breadth of dependencies, the abused group showed a larger depth of dependencies than the non-abused group. In other words, the abused group showed greater variation in the range of situations their resource people provided. Such a pattern might occur, for example, if the individual depended on most other people for very little but showed considerable dependency on one or two resources, perhaps including the self.

Repertory grid technique has proved valuable in exploring the construing of survivors of sexual abuse, including their tendency to view the self as different from others (Erbes and Harter, 2002). It may be that the dependency grid, particularly if its analysis is not limited to the diversity index, can 
elucidate the predicaments and interpersonal relationships of abuse survivors, as indeed of other individuals in both clinical and non-clinical settings. For example, consideration of, and experimentation, with both the breadth and the depth of dependencies may be a useful focus for therapy with some clients.

\section{References}

Alexander, P.C. \& Follette, V.M. (1987). Personal constructs in the group treatment of incest. In R.A. Neimeyer and G.J. Neimeyer (eds.), Personal Construct Therapy Casebook, pp. 211-229. New York: Springer.

Bell, R. C. (2001) Some new measures of the dispersion of dependency in a situation-resource grid. Journal of Constructivist Psychology, 14, 227234.

Bell, R.C. (2004) Predictive Relationships in Repertory Grid data: A new elaboration of Kelly's Organization Corollary. Journal of Constructivist Psychology, 17, 281-295

Bell, R. C. (2009) GRIDSTAT5: A program for analysing the data of a repertory grid. [Computer software] Melbourne: Author

Bhandari, S. (1998). Family characteristics and long-term effects of childhood sexual abuse. Unpublished Ph.D. thesis, University of Hertfordshire.

Bhandari, S., Winter, D., Messer, D., \& Metcalfe, C. (2009). Family

characteristics and long-term effcts of childhood sexual abuse. Submitted to British Journal of Clinical Psychology

Chiari, G., Mancini, F., Nicolo, F., \& Nuzzo, M.L. (1990). Hierarchical organization of personal construct systems in terms of the range of convenience. International Journal of Personal Construct Psychology, $\underline{3}$, 281-311. 
Chiari, G., Nuzzo, M.L., Alfano, V., a, P., D'Andrea, T., Di Battista, G., Plata, P., \& Stiffan, E. (1994). Personal paths of dependency. Journal of Constructivist Psychology, $\underline{7}, 17-34$.

Erbes, C.R. \& Harter, S.L. (2002). Constructions of abuse: understanding the effects of childhood sexual abuse. In J.D. Raskin \& S.K. Bridges (eds.), Studies in Meaning: Exploring Constructivist Psychology. New York: Pace University Press, pp. 27-48.

Fransella, F., Bell, R., and bannnister, D. (2004). A Manual for Repertory Grid Technique. Chichester: Wiley.

Hinkle, D.N. (1965). The change of personal constructs from the viewpoint of a theory of construct implications. Unpublished doctoral dissertation, Ohio State University.

Kelly, G.A. (1955). The Psychology of Personal Constructs. New York: Norton (reprinted by Routledge, 1991).

Landfield, A.W. and Scmittdiel, C.J. (1983). The Interpersonal Transaction Group: Evolving measurements in the pursuit of theory. In J. AdamsWebber and J.C. Mancuso (eds.), Applications of Personal Construct Theory, pp. 207-218. Toronto: Academic Press.

Minuchin, S. (1974). Families and Family Therapy. Cambridge, MA: Harvard University Press.

Shye, S. (1985) Multiple Scaling: The Theory and Application of Partial Order Scalogram Analysis. Amsterdam: North Holland.

Walker, B.M. (1997). Shaking the kaleidoscope: dispersion of dependency and its relationships. In G.J. Neimeyer and R.A. Neimeyer (eds.), Advances in Personal Construct Psychology, vol. 4, pp. 63- 97. 
Walker, B.M., Ramsey, F.L., \& Bell, R.C. (1988). Dispersed and undispersed dependency. International Journal of Personal Construct Psychology, $\underline{1}$, 63-80. 
Table 1 Characterizing Hierarchical Configurations by Differentiation and Variation in Coverage.

\begin{tabular}{lll}
\hline & Figure 4 Configuration & Figure 6 Configuration \\
\hline Differentiation & 0.37 & 0.79 \\
\hline variation in coverage & 0.79 & 0.08 \\
\hline
\end{tabular}


Table 2 Correlations among summary measures.

\begin{tabular}{llll}
\hline & $\begin{array}{l}\text { Breadth of POSAC } \\
\text { hierarchy }\end{array}$ & $\begin{array}{l}\text { Depth of POSAC } \\
\text { hierarchy }\end{array}$ & $\begin{array}{l}\text { Dispersion of } \\
\text { dependency }\end{array}$ \\
\hline $\begin{array}{l}\text { Breadth of POSAC } \\
\text { hierarchy }\end{array}$ & $\mathbf{. 6 2 * *}$ & $-.32^{* *}$ & $.60^{* *}$ \\
$\begin{array}{l}\text { Depth of POSAC } \\
\text { hierarchy }\end{array}$ & $-.34 * *$ & $.33 * *$ & .20 \\
$\begin{array}{l}\text { Dispersion of } \\
\text { dependency }\end{array}$ & $.60 * *$ & .15 &. $\mathbf{7 4 * *}$ \\
\hline$* * \mathrm{p}<.001$ & & &
\end{tabular}


Table 3. Means scores by Source of subject.

\begin{tabular}{|c|c|c|c|}
\hline & Clinic & University & \\
\hline $\begin{array}{l}\text { Dispersion of } \\
\text { Dependency }\end{array}$ & .681 & .791 & $F=22.1, d f: 1,105, p=.000$ \\
\hline $\begin{array}{l}\text { Breadth of } \\
\text { POSAC } \\
\text { Hierarchy }\end{array}$ & .555 & .641 & $F=9.2, d f: 1,105, p=.003$ \\
\hline $\begin{array}{l}\text { Depth of } \\
\text { POSAC } \\
\text { Hierarchy }\end{array}$ & .476 & .488 & $F=0.23, d f: 1,105, p=.635$ \\
\hline
\end{tabular}


Table 4. Mean Dispersion of Dependency by Group [Abused / Control] and Dependency Grid [Child / Adult].

\begin{tabular}{llll}
\hline $\begin{array}{l}\text { Dispersion of } \\
\text { dependency }\end{array}$ & Child Dependency & Adult Dependency & Average \\
\hline Control Group & .74 & .78 & .76 \\
Abused Group & .68 & .74 & .71 \\
\hline Average & .71 & .76 & \\
\hline
\end{tabular}


Table 5. Mean Breadth of POSAC hierarchy by Group [Abused / Control] and Dependency Grid [Child / Adult].

\begin{tabular}{llll}
\hline $\begin{array}{l}\text { Breadth of POSAC } \\
\text { hierarchy }\end{array}$ & Child Dependency & Adult Dependency & Both \\
\hline Control Group & .61 & .66 & .63 \\
Abused Group & .51 & .62 & .55 \\
\hline Overall & .56 & .63 & \\
\hline
\end{tabular}


Table 6. Mean Depth of POSAC hierarchy by Group [Abused / Control] and Dependency Grid [Child / Adult].

\begin{tabular}{llll}
\hline $\begin{array}{l}\text { Depth of POSAC } \\
\text { hierarchy }\end{array}$ & Child Dependency & Adult Dependency & \\
\hline Control Group & .45 & .45 & .45 \\
Abused Group & .51 & .51 & .51 \\
\hline & .48 & .48 & \\
\hline
\end{tabular}




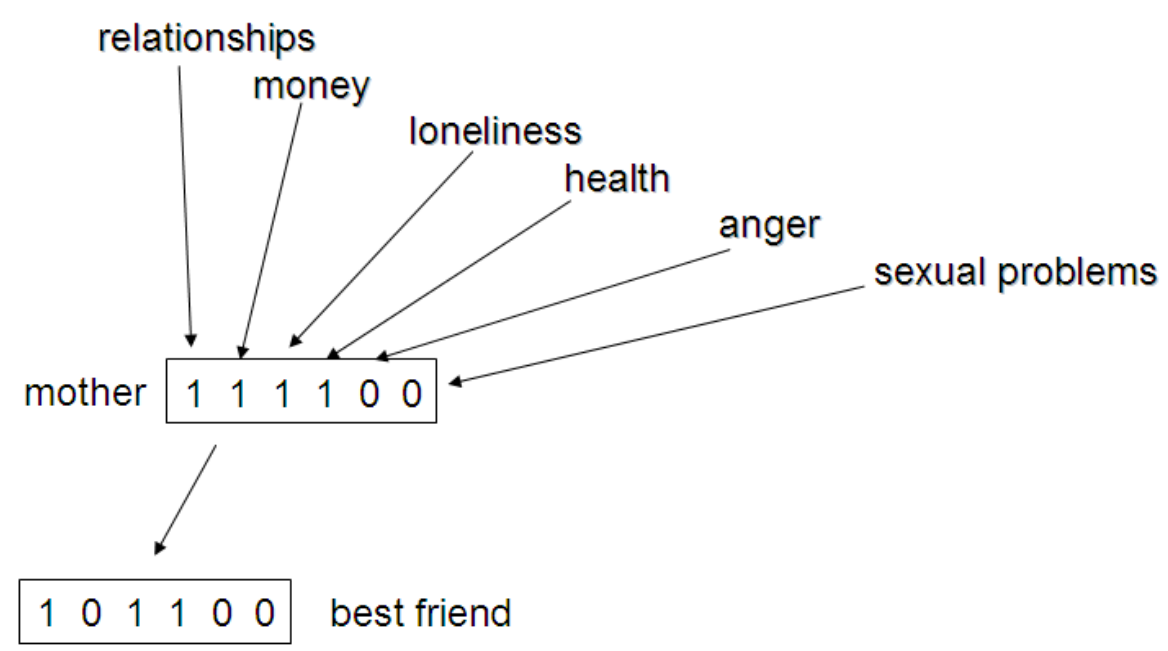

Figure 1. Diagrammatic relationship of the relationship between mother and best friend in dependency grid data. 


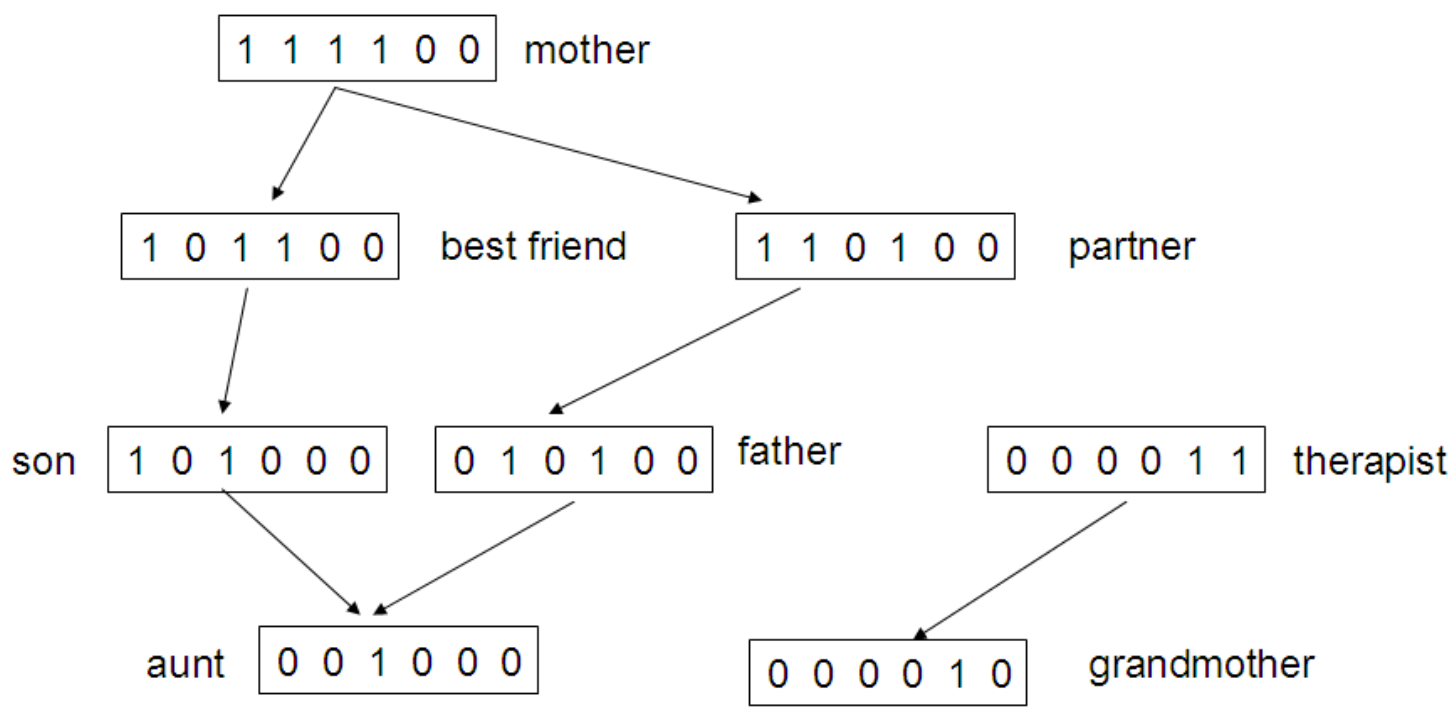

Figure 2. Diagrammatic relationship of hierarchical relationships in hypothetical dependency grid data. 


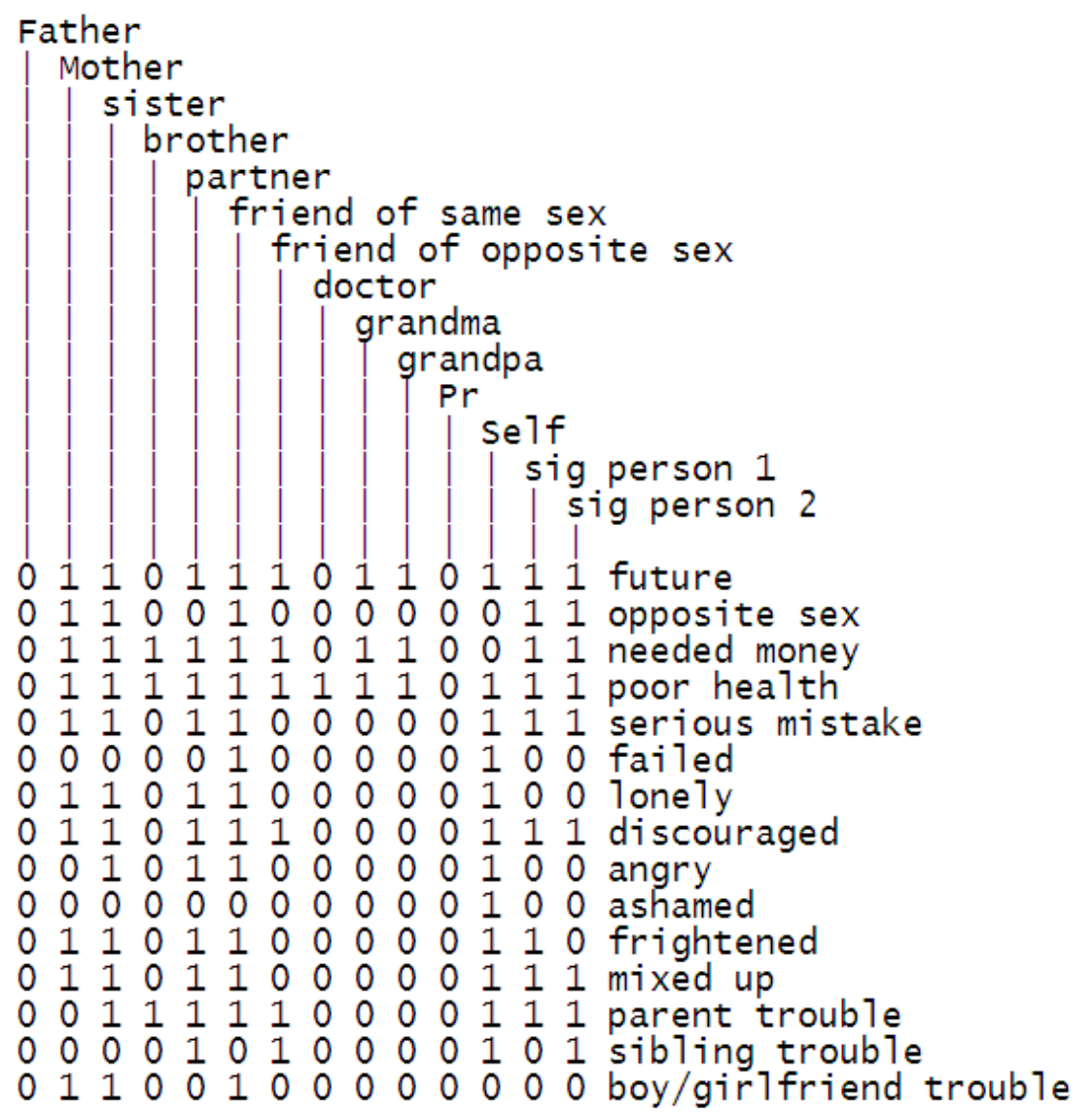

Figure 3. An actual Dependency Grid 


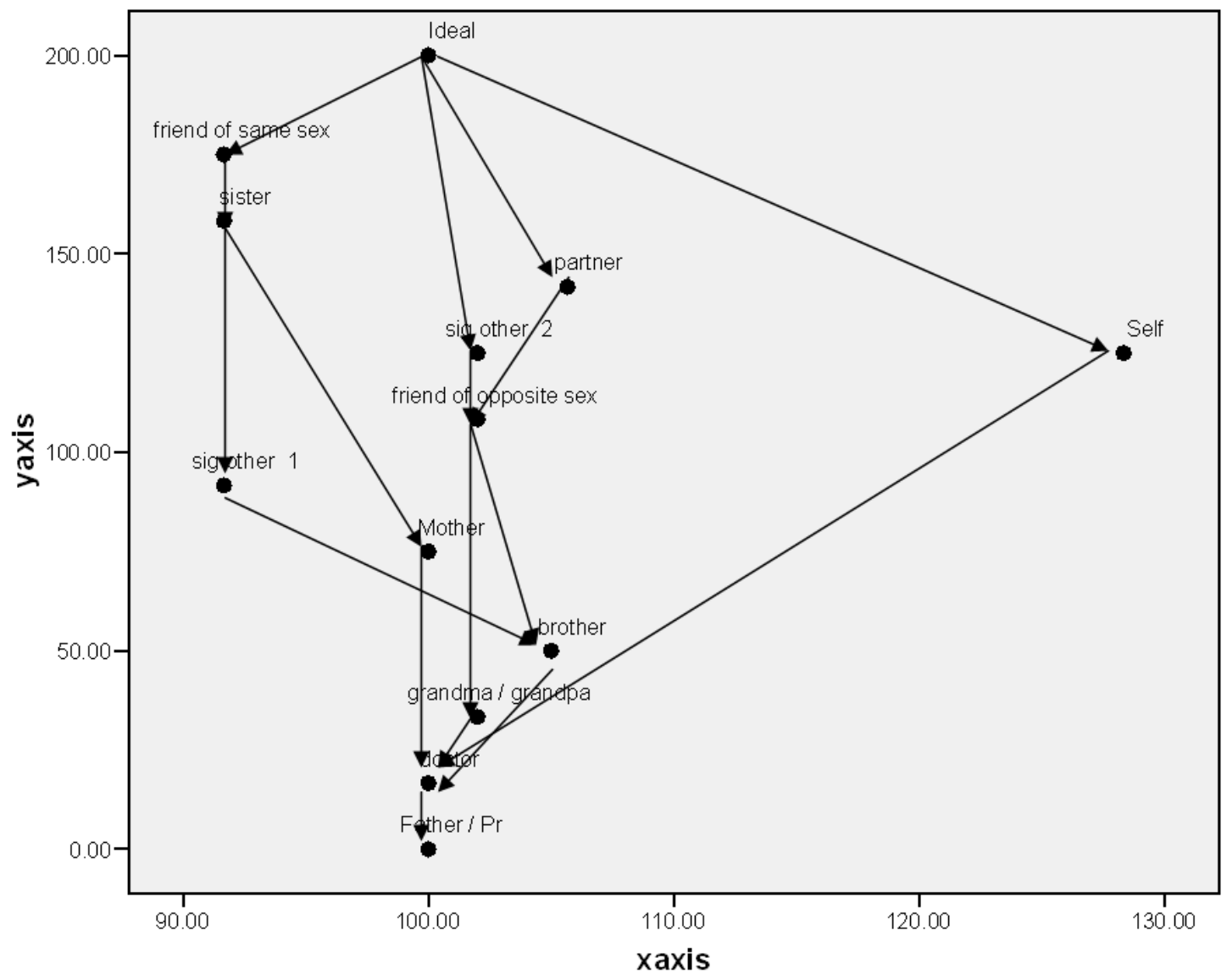

Figure 4. POSAC representation of hierarchical relationships among resources for the dependency grid of Figure 3. 


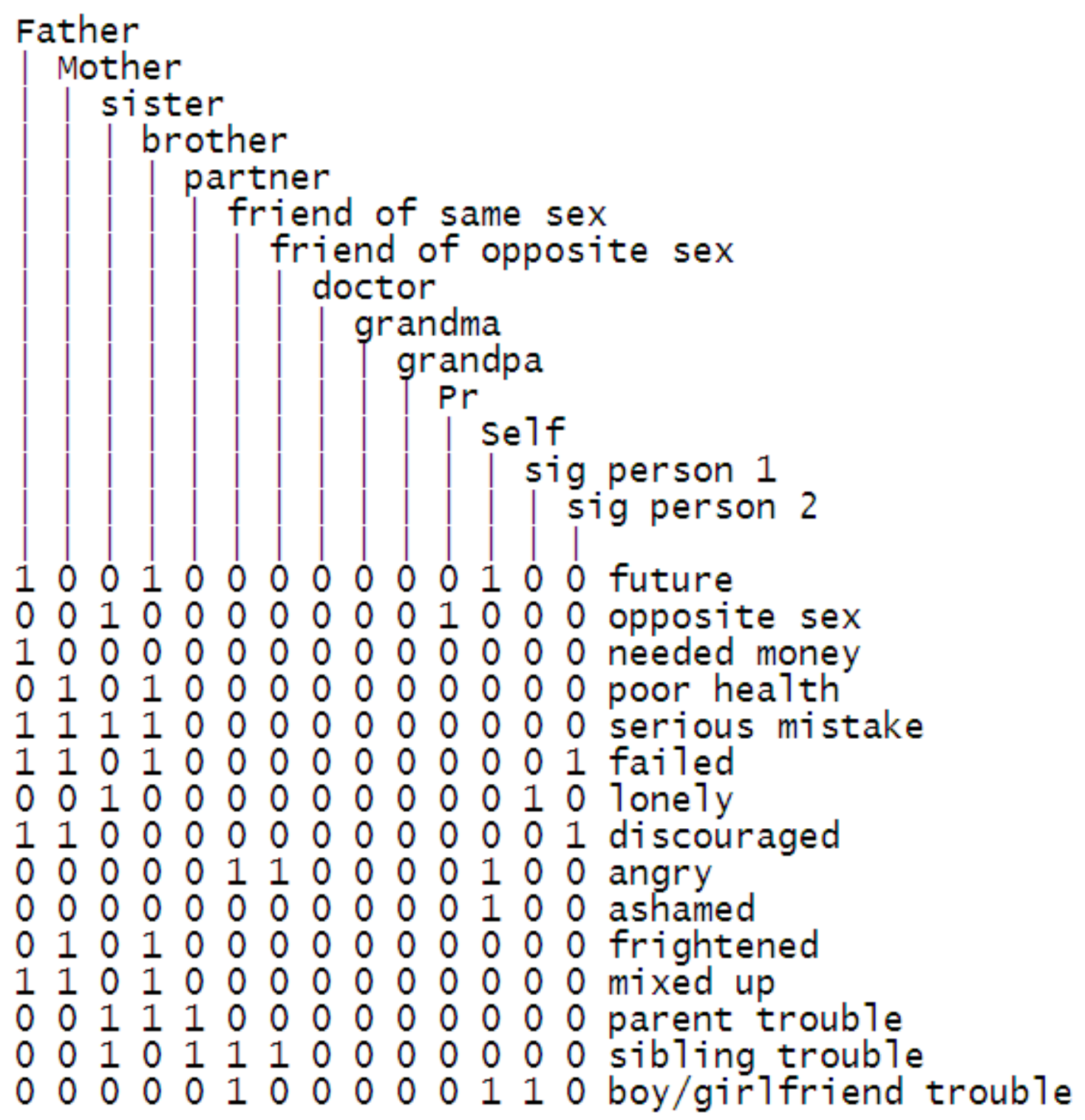

Figure 5. Another actual Dependency Grid 


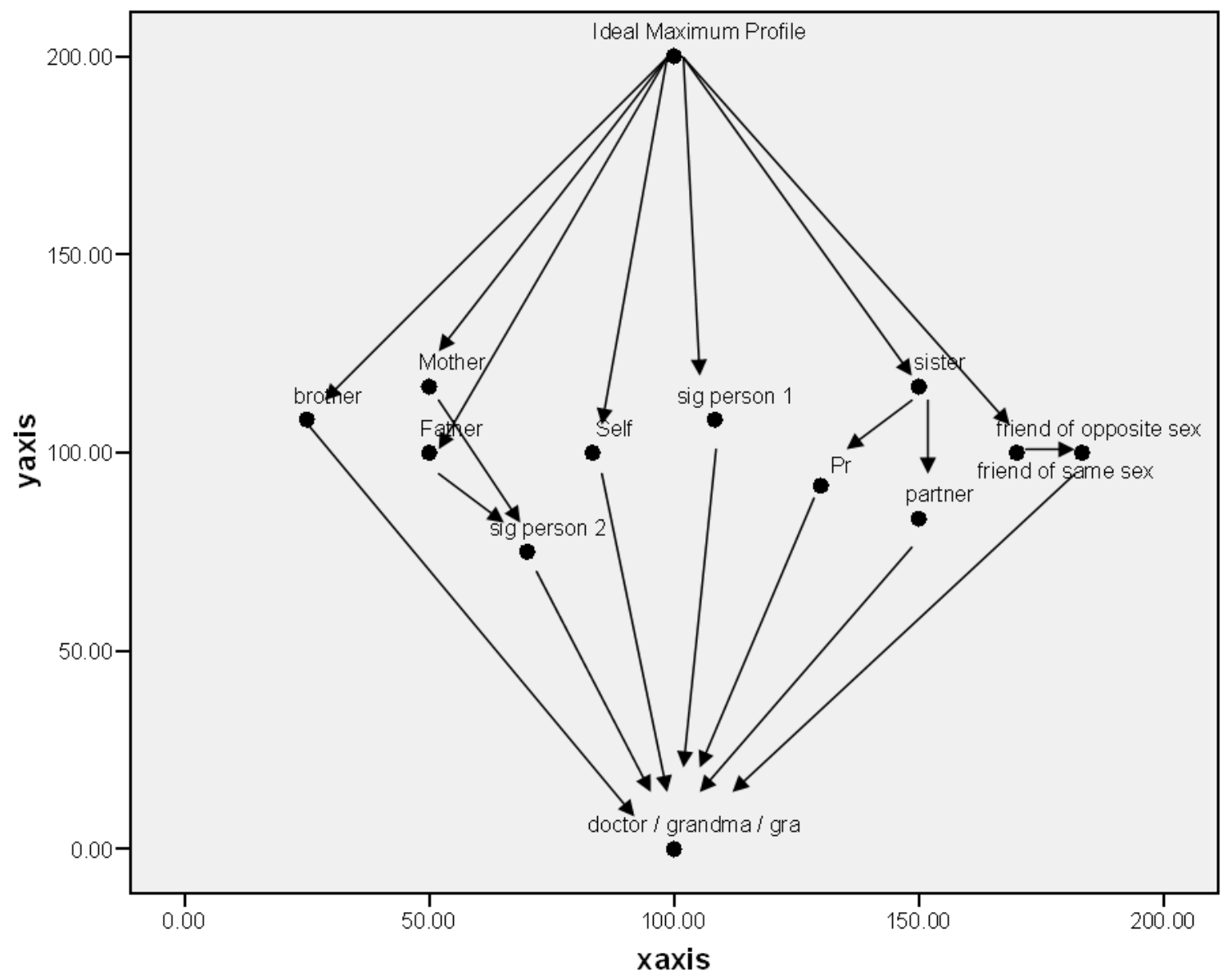

Figure 6. POSAC representation of hierarchical relationships among resources for the dependency grid of Figure 5. 